\title{
Using Completely Randomized Design of Parallel Linear Model for Estimating the Biological Potency of Human Insulin Drugs: An Empirical Study
}

\author{
Mohamed RA ${ }^{1}$ and Mariam $\mathrm{HM}^{2}$ \\ ${ }^{1}$ Department of Applied Statistics and Econometrics, Institute of Statistical Studies and Research, Egypt \\ ${ }^{2}$ Hormone evaluation lab, National organization of drug control and research (NODCAR), Egypt
}

Submission: August 31, 2017; Published: October 23, 2017

*Corresponding author: Mohamed R Abonazel, Department of Applied Statistics and Econometrics, Institute of Statistical Studies and Research, Egypt, Tel: 201221876008; Email: mabonazel@hotmail.com

\section{Abstract}

In this article, we propose using the completely randomized design of parallel linear model in the statistical analysis of the biological assay of Human Insulin injection used by patients with Diabetes mellitus type II. Check the efficacy of insulin drugs should take place because either lower or higher efficacy from the acceptable limits has its complication. Four different batches of insulin product were analyzed by using human insulin reference standard. Estimating the biological activity as a relative potency (relative to the standard) of each batch the result of the four batches was within the acceptable limit of the drug specification. Moreover, we compare our bioassay results with the chemical assay (using HPLC) results of the same batches. Then, we found that all the results were within the acceptable limits and led us to the same conclusions.

Abbreviations: PLM: Parallel Line Model; CRD: Completely Randomized Design; NODCAR: National Organization of Drug Control and Research

Introduction

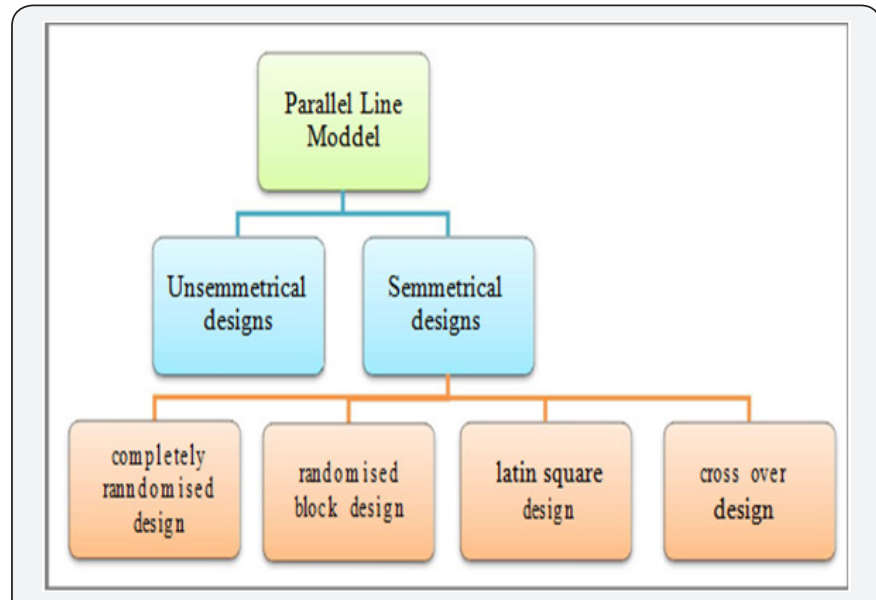

Figure 1: Types of parallel line model.

The Parallel line model (PLM) is an important model used in biological analysis (called also bioassay) of various types of drugs such as antibiotics, vitamins, several types of hormones as shown in United States Pharmacopeia (USP) [1]; British Pharmacopoeia (BP) [2]. The parallel line model can be done as a balanced or symmetric assay or unbalanced or asymmetric assay. A parallel line assay in which each of the preparations has an equal number of doses and an equal number of subjects is allotted to each of the doses, is called a symmetrical parallel line assay $[3,4]$. In addition, in the symmetrical designs of PLM, the allocation of experimental units (animals, tubes, etc.) to different treatments may be made in various ways; completely randomized design (CRD), randomized block design, Latin square design and cross-over design [2,3], as shown in Figure 1.

The analysis is based on a regression of the response variable against the natural logarithm of the dose variable. A separate line is fitted on each preparation, subject to a constraint that they should be parallel. Figure 2 Show's an illustration of the parallel line model where the logarithm of the doses is represented on the horizontal axis with the lowest concentration on the left and the highest concentration on the right. The responses are indicated on the vertical axis. The individual responses to each treatment are indicated with black dots. The 2 lines are the calculated $\ln$ (dose)-response relationship for the standard and the unknown. The more nearly correct the assumed potency of the unknown, 
the closer the two lines will be together, for they should give equal responses at equal doses. The horizontal distance between the lines represents the "true" potency of the unknown, relative to its assumed potency. The greater the distance between the two lines, the poorer the assumed potency of the unknown [2].



Figure 2: Illustration of parallel line model.

The PLM is used in estimating of the biological potency of many hormones such as insulin. Insulin was discovered in 1921, it is a hormone secreted from the pancreas responsible for decreasing blood glucose level [5] Diabetes mellitus type II is a metabolic disorder resulting from a defect in insulin secretion, thus increasing blood glucose level. Diabetes finally leads to more complications and to prevent these complications insulin and its analogues are used as an extra support of insulin by Diabetic patient [6]. When treating patient with insulin drug the dose should be adjusted to maintain the blood glucose level normal so as to achieve good quality of life to the diabetic patient. If the dose increased or decreased than the need of patient hypoglycemia or hyperglycemia will take place and each of them has their complication [7]. The dose adjustment is not a simple issue it needs first to estimate the potency of the insulin.

Now insulin is a medicine that is manufactured and administered worldwide [8]. Assaying potency in insulin preparations (analysis of insulin) is often performed by chemical methods. Although these methods are sensitive and accurate to detect insulin potency in the insulin preparations, the chemical methods are NOT enough. Chemical methods estimate only the amount of insulin present in the preparation as a concentration, so it estimates ONLY the chemical potency [9]. For purposes of assay, potency assignment, and dosing, insulin was transitioned from biological potency units to a mass balance assigned value (chemical potency or concentration) in the late 1980's and has since been treated like a chemical [8]. However, the potency estimated by chemical methods are found not always in good correlation with the hypoglycemic activity of insulin (biological potency of insulin) [9].

According the British Pharmacopeia 2017, the insulin assay is done only chemically by HPLC and this is satisfactory. The USP 2017 has mandated that all insulin preparations should have their hypoglycemic activity assayed by measuring the glucose-lowering activity. Thus a biological assay (bioassay) of insulin is required. The USP procedure is an extremely timeconsuming task and the results obtained have been often found to be highly variable [9]. Moreover, in case of using rabbits this needs more space for husbandry and it is also costly. In British pharmacopeia 1988, estimating biological potency of insulin is done also as mentioned in USP by using cross over design but in mice instead of rabbit [10]. Which is also time-consuming task as the experiment takes place on the same animal two times; in addition, in case of mice collecting blood two times 150 minutes interval (as mentioned in [10]) sometimes fatal and cause loss of many data.

In this work, completely randomized design in human insulin bioassay using mice is suggested and comparing the results with the results obtained from HPLC assay of insulin against the same standard. This article is organized as follows; section 2 provides an over view of biological assay in general will be introduced while section 3 will discuss the completely randomized design of the parallel linear model. Moreover, section 4 will introduce an empirical study of statistical analysis of bioassay of four different batches of human insulin drug against reference standard by using CRD of PLM and comparing the bioassay results with the results obtained from the chemical assay of the same batches using HPLC. Finally, Section 5 offers the concluding remarks.

\section{Biological Assays}

Biological assays are methods for the estimation of a potency of a material by its effect on a living matter [11].

\section{Structure of bioassay}

The typical bioassay involves a stimulus (insulin) applied to a subject (mice). The intensity of the stimulus can be varied according to the dose given to the subject and this dose can be measured (perhaps as a concentration). Application of the stimulus is followed by a change in some measurable characteristics (decreasing blood glucose level) of the subject; the magnitude of this change depends upon the dose. A measurement of this characteristic (measuring glucose level in blood) is the response of the subject [3]. Bioassay is a planned experiment in which two stimuli, one with known preparation known as standard and another with unknown preparation known as test are applied to subjects. The comparison is made on the basis of two sets of doses, one from standard preparation and the other from test preparation such that they produce the same response.

\section{Principle of bioassay}

The basic principle of bioassay is to compare the test substance with the international standard preparation of the same and to find out how much test substance is required to produce the same biological effect, as produced by the standard. The standards are internationally accepted samples of drugs 
maintained and recommended by the Expert Committee of the Biological Standardization of W.H.O. [11].

\section{Importance of bioassay}

Bioassays, as compared to other methods of assays (e.g. chemical or physical assay) are less accurate, less elaborate, more laborious, more troublesome and more expensive. However, bioassay is the only method of assay if

a. Active principle of drug is unknown or cannot be isolated in a pure form.

b. Chemical method is either not available or if available, it is too complex

c. Chemical composition is not known.

d. Chemical composition of drug differs but have the same pharmacological action.

Moreover, even if chemical methods are available and the results of bioassay conflict with those of the chemical assay, the bioassay is relied upon and not the chemical assay, since it is the assessment on living organisms [11].

\section{Purpose of bioassay}

The main purpose of bioassay is to estimate the relative potency of the test preparation relative to the standard preparation [12]. The purpose of estimating the relative potency by bioassay is to ascertain the potency of a drug and hence it serves as the quantitative part of any screening procedure (quality control on drugs). Other purpose of bioassay is to standardize the preparation so that each contains the uniform specified pharmacological activity $[3,11]$.

\section{Types of bioassay}

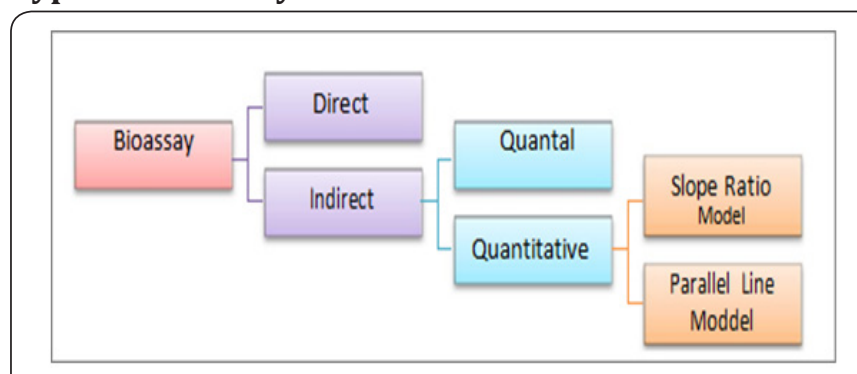

Figure 3 : Types of Bioassay.

There are two main types of biological assay as shown in Figure 3 direct assay and indirect assay. Moreover, the indirect assay is classified according to the nature of the response recorded into Indirect assay based upon quantal ("all-orTable 1: Structure of symmetric parallel line assay data. nothing") responses, such as death is or is not produced and Indirect assays based upon quantitative responses, such as the weight of an organ, the level blood glucose in blood [3]. Two statistical models are of interest as models for indirect assays with quantitative response; the parallel-line model and the slope-ratio model $[2,3]$.

\section{The CRD Model}

\section{Model assumptions}

The application of the RCD in the symmetric PL model is dependent on the fulfillment of the following assumptions $[3,13,14]$.

Assumption 1: Randomization. The different treatments have been randomly assigned to the experimental units.

Assumption 2: Normality. The responses to each treatment are normally distributed. However, British pharmacopeiastated that minor deviations from this assumption will in general not introduce serious flaws in the analysis as long as several replicates per treatment are included [13].

Assumption 3: Homogeneity of variance. The standard deviations of the responses within each treatment group of both standard and unknown preparations don't differ significantly from one another.

Assumption 4: Linearity. The relationship between the logarithm of the dose and the response can be represented by a straight line over a range of doses used (if the assay consists of 3 doses of each preparation or more).

Assumption 5: Parallelism. For any unknown preparation in the assay, the straight line is parallel to that of standard.

\section{Model structure}

Let $h$ is number of preparations including the standard. Let the number of doses of each of the preparations be $d$. Let $n$ subjects be allotted to each of the doses and a suitable response be measured from each subject. Denoting the response of the $k^{\text {th }}$ subject allotted to the $j^{\text {th }}$ dose of the $j^{\text {th }}$ preparation by $y_{i j k}$, the response data are first arranged as in Table 1-3. The analysis of variance is now completed as follows. Each sum of squares is divided by the corresponding number of degrees of freedom to give mean squares. The mean square for each variable to be tested is now expressed as a ratio to a mean square error ( $\square S E$ ) and the significant of these values (known as F-ratios) are assessed by comparing it with the tabulated F-ratio (Table 2).

\begin{tabular}{|c|c|c|c|c|c|c|c|c|c|c|c|c|c|}
\hline \multirow{2}{*}{ Units } & \multicolumn{4}{|c|}{ Standard preparation (1) } & \multicolumn{4}{|c|}{ 1st Test preparation (2) } & \multirow{2}{*}{$\begin{array}{c}\text { preparation } \\
\text { (i) } \\
\ldots . \\
\end{array}$} & \multicolumn{4}{|c|}{ Last test preparation } \\
\hline & dose 1 & dose 2 & $\ldots j \ldots$ & dose d & dose 1 & dose 2 & $\ldots \boldsymbol{j} \ldots$ & dose $\mathrm{d}$ & & dose 1 & dose 2 & $\ldots j \ldots$ & dosed \\
\hline 1 & $y_{111}$ & $y_{121}$ & $\ldots y_{1 j \mid l} \ldots$ & $y_{1 d 1}$ & $y_{211}$ & $y_{221}$ & $\ldots y_{2 j 1} \ldots$ & $y_{2 d 1}$ & $\ldots y_{i j 1} \ldots$ & $y_{h 11}$ & $y_{h 21}$ & $\ldots y_{h j 1} \ldots$ & $y_{h d 1}$ \\
\hline 2 & $y_{112}$ & $y_{112}$ & $\ldots y_{1 j 2} \ldots$ & $y_{1 d 2}$ & $y_{212}$ & $y_{222}$ & $y_{2 j 2}$ & $y_{2 d 2}$ & $\ldots y_{i j 2} \ldots$ & $y_{h 12}$ & $y_{h 22}$ & $\ldots y_{h j 2} \ldots$ & $y_{\text {hd } 2}$ \\
\hline
\end{tabular}




\section{Biostatistics and Biometrics Open Access Journal}

\begin{tabular}{|c|c|c|c|c|c|c|c|c|c|c|c|c|c|}
\hline . & . & . & . & . & . & . & . & . & . & . & . & . & . \\
\hline . & . & . & . & . & . & . & . & . & . & . & . & . & . \\
\hline . & . & . & . & . & . & . & . & . & . & . & . & . & . \\
\hline $\mathrm{n}$ & $y_{11 n}$ & $y_{12 n}$ & $\ldots y_{1 j n} \ldots$ & $y_{1 d n}$ & $y_{21 n}$ & $y_{22 n}$ & $\ldots y_{2 j n} \ldots$ & $y_{2 d n}$ & $\ldots y_{i j n} \ldots$ & $y_{h 1 n}$ & $y_{h 2 n}$ & $\ldots y_{h j n} \ldots$ & $y_{h d n}$ \\
\hline
\end{tabular}

Number of preparations including the standard: $i=1, \ldots, h$

Number of doses in each preparation: $j=1, \ldots, d$

Number of observations in each dose: $k=1, \ldots, n$

Table 2: Formulas for parallel line assays with d doses of each preparation.

\begin{tabular}{|c|c|c|c|c|}
\hline & Standard preparation (1) & 1st Test preparation (2) & ith preparation (i) & Last test preparation $(h)$ \\
\hline $\begin{array}{l}\text { Mean response } \\
\text { lowest dose }\end{array}$ & $\overline{Y_{11}}=\frac{1}{n} \sum_{k=1}^{n} Y_{11 k}$ & $\bar{Y}_{21 .}=\frac{1}{n} \sum_{k=1}^{n} Y_{21 k}$ & $\ldots \bar{Y}_{i 1} \ldots$ & $\bar{Y}_{h 1}$ \\
\hline $\begin{array}{l}\text { Mean response } \\
2 \text { nd dose }\end{array}$ & $\bar{Y}_{12 .}=\frac{1}{n} \sum_{k=1}^{n} Y_{12 k}$ & $\bar{Y}_{22 .}=\frac{1}{n} \sum_{k=1}^{n} Y_{22}$ & $\ldots \overline{Y_{i 2}} \ldots$ & $\bar{Y}_{h 2 .}$ \\
\hline . & . & . & . & . \\
\hline . & . & . & . & . \\
\hline . & . & . & . & . \\
\hline $\begin{array}{c}\text { Mean response jth } \\
\text { dose }\end{array}$ & $\overline{Y_{1}}$, & $\bar{Y}_{2 j}$ & $\overline{Y_{i j}}$ & $\bar{Y}_{h j}$ \\
\hline . & . & . & . & . \\
\hline . & . & . & . & . \\
\hline . & . & . & . & . \\
\hline $\begin{array}{l}\text { Mean response } \\
\text { highest dose }\end{array}$ & $\bar{Y}_{1 d .}=\frac{1}{n} \sum_{k=1}^{n} Y_{1 d k}$ & $\bar{Y}_{2 d .}=\frac{1}{n} \sum_{k=1}^{n} Y_{2 d k}$ & $\ldots \bar{Y}_{i d} \ldots$ & $\bar{Y}_{h d .}$ \\
\hline Total preparation & $P_{1}=\sum_{j=1}^{d} \bar{Y}_{1 j}$ & $P_{2}=\sum_{j=1}^{d} \bar{Y}_{2 j}$ & $\ldots P_{i} \ldots$ & $P_{h}$ \\
\hline Linear contrast & $L_{1}=\sum_{j=1}^{d} j \bar{Y}_{1 j .}-\frac{1}{2}(d+1) P_{1}$ & $L_{2}=\sum_{j=1}^{d} j \bar{Y}_{2 j .}-\frac{1}{2}(d+1) P_{2}$ & $\ldots L_{i} \ldots$ & $L_{h}$ \\
\hline \multicolumn{5}{|c|}{ Additional formulae } \\
\hline$H_{P}=\frac{n}{d}$ & $H_{L}=\frac{12 n}{\left(d^{3}-d\right)}$ & $K=\frac{n\left(\sum_{i-1}^{h} p_{i}\right)^{2}}{h d}$ & \multicolumn{2}{|c|}{$\frac{1}{h d n} \sum_{i=1}^{h} \sum_{j=1}^{d} \sum_{k=1}^{n} y_{i j k}$} \\
\hline
\end{tabular}

Table 3: Formulae to calculate the sum of squares and degrees of freedom.

\begin{tabular}{|c|c|c|c|}
\hline Source of Variation & Degrees of freedom & Sum of squares & Mean square \\
\hline preparations & $h-1$ & $S S_{\text {prep }}=H_{p}\left(\sum_{i=1}^{h} p_{i}^{2}\right)-k$ & $S S_{\text {prep }} / h-1$ \\
\hline Linear regression & h & $S S_{r e g}=\frac{1}{h} H_{L}\left(\sum_{i=1}^{h} L_{i}\right)^{2}$ & $S S_{\text {reg }} / 1$ \\
\hline Non-parallelism & $h-1$ & $S S_{p a r}=H_{L}\left(\sum_{i=1}^{h} L_{i}^{2}\right)-S S_{r e g}$ & $S S_{p a r} / h-1$ \\
\hline Non-linearity* & $h(d-2)$ & $S S_{\text {lin }}=S S_{\text {treat }}-S S_{\text {prep }}-S S_{\text {reg }}-S S_{\text {par }}$ & $S S_{l i n} / h(d-2)$ \\
\hline Treatments & $h d-1$ & $S S_{\text {treat }}=n\left(\sum_{i=1}^{h} \sum_{j=1}^{d} \bar{Y}_{i j .}^{2}\right)-K$ & $S S_{\text {treat }} / h d-1$ \\
\hline Residual error & $h d(n-1)$ & $S S_{\text {res }}=S S_{\text {tot }}-S S_{\text {treat }}$ & $s^{2}=\frac{S S_{r e g}}{h d(n-1)}$ \\
\hline Total & $n h d-1$ & \multicolumn{2}{|c|}{$\sum_{i=j}^{h} \sum_{j=1}^{d} \sum_{k=1}^{n}\left(y_{i j k}-\bar{y}_{\ldots}\right)^{2}$} \\
\hline
\end{tabular}


Assay results are said to be "statistically valid" if the outcome of the analysis of variance is as follows:

a. The linear regression term is significant. If this criterion is not met, it is not possible to calculate 95 percent confidence limit.

b. The term of non-parallelism is not significant. If it is significant we can omit the preparation that cause this significance and restart the analysis from the beginning.

c. The term of non-linearity is not significant.

When statistical validity is established, potencies and confidence limits can be estimated (Table 3).

The common slope (b) for assays of $d$ doses of each preparation is obtained from:

$$
b=\frac{H_{L}\left(\sum_{i=1}^{h} L_{i}\right)}{\operatorname{Inh}}
$$

Where $I$ is the $I n$ of the ratio between adjacent doses of any preparation. The logarithm of the potency ratio of a test preparation is:

$$
M_{i}=\frac{p_{i}-p_{1}}{d b}, i=2,3, \ldots . . h .
$$

The antilogarithm of $M_{i}$, is an estimate of the true potency of each unknown.

\section{Empirical study}

The analysis took place at Hormone Evaluation Lab in National Organization of Drug Control and Research, Egypt. Analysis of insulin drugs of a stated potency $100 \mathrm{IU} / \mathrm{ml}$ (the manufacturer stated that the concentration of insulin is 100IU/ $\mathrm{ml}$ ) against insulin reference standard to check the biological potency of four batches of an imported insulin drug. The assay followed taking into account the strain sensitivity to the dose. The first dose data (non crossover) were analyzed [10].

Now we have 5 preparations (standard preparation and four test preparations). Two dilutions was performed for each preparation using acidic physiological saline; $5 \mathrm{mU} / \mathrm{ml}$ and $15 \mathrm{mU} / \mathrm{ml}$. Thus, ten treatments will be injected in ten mice per each.

Each mouse receives $0.1 \mathrm{ml} / 10 \mathrm{gm}$ body weight. The final dose received by mice is 10

i. low dose : $0.5 \mathrm{mU}$ insulin per 10 gm body weight

ii. High dose: $1.5 \mathrm{mU}$ insulin per 10 gm body weight

After 25 minutes of insulin injection, the blood glucose concentration of each mouse is estimated using a unit of $\mathrm{mg} / \mathrm{dl}$.

\section{The data (Table 4)}

\begin{tabular}{|c|c|c|c|c|c|c|c|c|c|c|}
\hline \multicolumn{11}{|c|}{ preparation } \\
\hline \multirow{2}{*}{ Animal } & \multicolumn{2}{|c|}{1} & \multicolumn{2}{|c|}{2} & \multicolumn{2}{|c|}{3} & \multicolumn{2}{|c|}{4} & \multicolumn{2}{|c|}{5} \\
\hline & \multicolumn{2}{|c|}{ (standard) } & \multicolumn{2}{|c|}{ 1st test } & \multicolumn{2}{|c|}{ 2nd test } & \multicolumn{2}{|c|}{ 3rd test } & \multicolumn{2}{|c|}{ 4th test } \\
\hline \multirow{2}{*}{ unit } & 1 & 2 & 1 & 2 & 1 & 2 & 1 & 2 & 1 & 2 \\
\hline & low & high & low & high & low & high & low & high & low & high \\
\hline 1 & 89.9 & 70.7 & 127.6 & 68.8 & 150.5 & 63.4 & 85.9 & 114.5 & 132 & 59.6 \\
\hline 2 & 134.7 & 69.7 & 159.9 & 72.2 & 150.5 & 56.8 & 145.8 & 73.2 & 143.8 & 79.2 \\
\hline 3 & 115.8 & 71.9 & 127.9 & 97.2 & 100 & 66.2 & 155.6 & 83.9 & 98.3 & 61.2 \\
\hline 4 & 134.3 & 66.9 & 126.6 & 66.2 & 118.5 & 62.5 & 155.9 & 58.7 & 130 & 62.5 \\
\hline 5 & 125.3 & 61.5 & 121.5 & 75.7 & 122.6 & 62.8 & 126.9 & 69.1 & 150.5 & 74.8 \\
\hline 6 & 141.4 & 100.9 & 128.6 & 49.5 & 127.6 & 64.4 & 123.6 & 63.1 & 118.5 & 112 \\
\hline 7 & 129.3 & 82.3 & 118.2 & 61.5 & 126.6 & 77.6 & 119.9 & 76 & 125.9 & 68.1 \\
\hline 8 & 151.9 & 72.9 & 192.3 & 74.4 & 130 & 56.8 & 101 & 113.9 & 110.8 & 58.7 \\
\hline 9 & 95.3 & 58 & 158.9 & 41.6 & 102.4 & 92.1 & 108.4 & 88.6 & 122.9 & 64 \\
\hline 10 & 133.3 & 67.5 & 132 & 62.8 & 108.1 & 59.6 & 120.9 & 63.1 & 133.3 & 71 \\
\hline
\end{tabular}

Table 4: Blood glucose level of each mice after 25 minutes following injection.

\section{Statistical analysis}

\section{Checking the assumptions}

Before analysis of the data, the five assumptions we mentioned must be checked:

Assumption 1: Mice of the same weight and same sex from the same farm are randomly distributed into ten cages.
Assumption 2: Test of normality is done by KolmogorovSmirnov test. The p-value for the test of all groups is higher than the chosen significance level (0.05) as shown in Table 5, conclude that the data follow the normal distribution.

Assumption 3: Test of homogeneity of variances is done by Bartlett's (1973) test. The p-value for test, as shown in Figure 4, is higher than the chosen significance level (0.05), concluding that the data is homogeneous. 


\section{Biostatistics and Biometrics Open Access Journal}

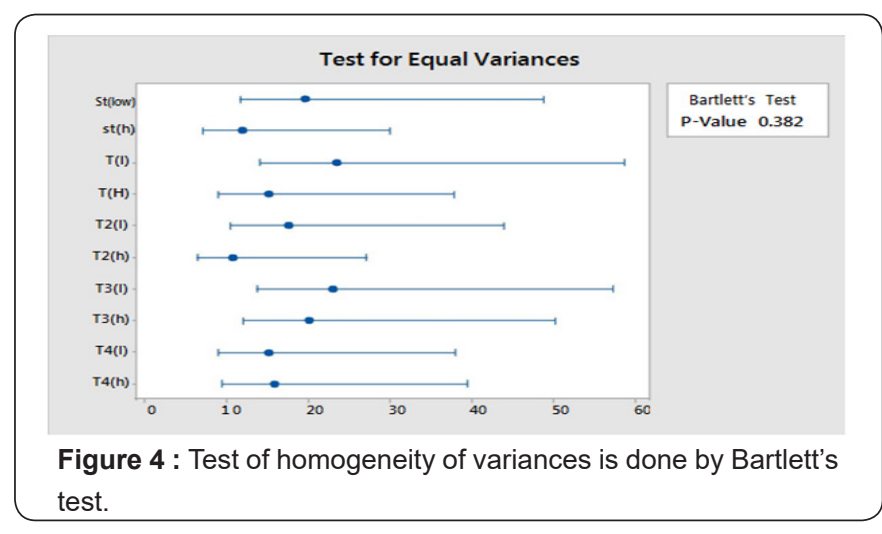

Table 5: Tests of normality.

\begin{tabular}{|c|c|c|}
\hline \multirow{2}{*}{ Group } & \multicolumn{2}{|c|}{ Kolmogorov-Smirnov test } \\
\cline { 2 - 3 } & Z-statistic & p-value \\
\hline Standard_low & 0.644 & 0.801 \\
\hline Standard_High & 0.878 & 0.423 \\
\hline Test_1_low & 1.02 & 0.249 \\
\hline Test_1_high & 0.579 & 0.891 \\
\hline Test_2_low & 0.505 & 0.961 \\
\hline Test_2_high & 0.951 & 0.326 \\
\hline Test_3_low & 0.495 & 0.967 \\
\hline Test_3_high & 0.591 & 0.876 \\
\hline Test_4_low & 0.411 & 0.996 \\
\hline Test_4_high & 0.687 & 0.733 \\
\hline
\end{tabular}

Assumption 4: Testing of linearity is not applicable here because this design consists of 2 doses for each preparation.

Assumption 5: Checking of parallelism. The analysis confirms a significant linear regression where the calculated $\mathrm{F}$ is greater than the tabulated $\left(F_{t a b}\right)$ one. Moreover, test of nonparallelism is not significant i.e. no significant difference in parallelism between groups as $F$ tabulated is greater than $F$ calculated. Figure 5 shows the parallelism of preparations (Table 6).

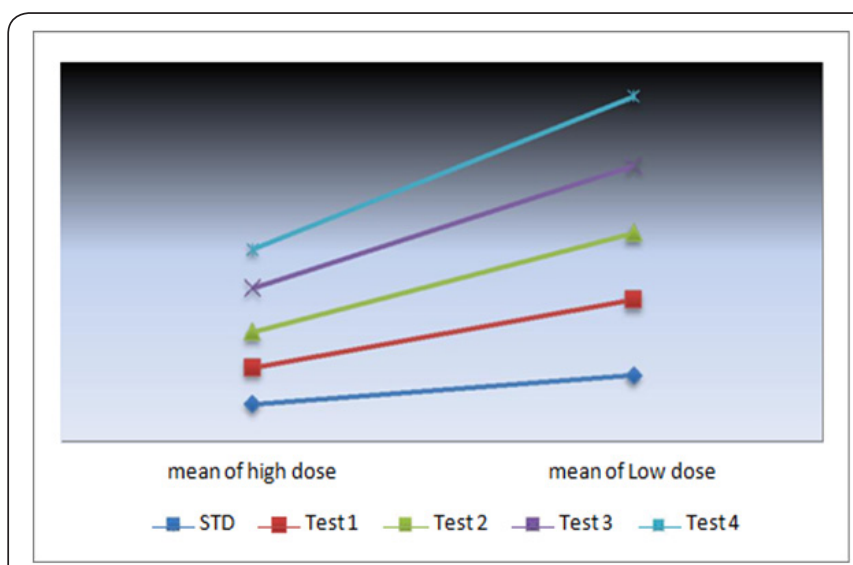

Figure 5 : Parallelism, where a line drawn from the high dose to the low dose for each preparation.

Now all Assumptions are fulfilled so the potency can be calculated.

Table 6: Analysis of variance.

\begin{tabular}{|c|c|c|c|c|c|}
\hline Source of variation & $\mathrm{df}$ & Sum of squares & Mean square & $F$ & 52.4 \\
\hline Linear regression & 1 & $S S_{\text {reg }}=79610.3$ & $M S_{\text {reg }}=79610.3$ & 1.679 & 3.841 \\
\hline Non-parallelism & 4 & $S S_{\text {par }}=2117.7$ & $M S_{\text {par }}=529.4$ & & \\
\hline Treatments & 9 & $S S_{\text {treat }}=82602.7$ & $M S_{\text {treat }}=9178.1$ & \\
\hline Error & 90 & $S S_{\text {res }}=28382$ & $M S E=315.4$ & \\
\hline Total & \multicolumn{3}{|c|}{$S S_{\text {tot }}=1$ 1 10984.7} \\
\hline
\end{tabular}

\section{Calculations of potency}

$$
\begin{aligned}
& b=\frac{H_{L}\left(\sum_{i=1}^{h} L_{i}\right)}{\operatorname{Inh}}=\frac{20 \times-141.1}{\operatorname{In}\left(\frac{1.5}{0.5}\right) \times 10 \times 5}=-51.4 \\
& M_{i}=\frac{p_{i}-p_{1}}{d b}=\frac{p_{i}-197.4}{2 \times-514.4} ; i=2, \ldots \ldots, 5
\end{aligned}
$$

Table 7: Potency results.

\begin{tabular}{|c|c|c|c|c|}
\hline \multirow{2}{*}{ Test } & \multirow{2}{*}{ HPLC assay } & \multirow{2}{*}{\begin{tabular}{c}
\multirow{2}{*}{$\begin{array}{c}\text { Biological } \\
\text { Potency }\end{array}$} \\
\cline { 4 - 5 }
\end{tabular}} & & \multicolumn{2}{|c|}{ Fiducial limits } \\
\hline Test 1 & $97.13 \%$ & $91.50 \%$ & $82 \%$ & $102 \%$ \\
\hline Test 2 & $95.97 \%$ & $107.70 \%$ & $97 \%$ & $119 \%$ \\
\hline Test 3 & $93.61 \%$ & $92.90 \%$ & $84 \%$ & $103 \%$ \\
\hline Test 4 & $97.70 \%$ & $99.70 \%$ & $90 \%$ & $111 \%$ \\
\hline
\end{tabular}

By taking the antilog of $M_{i}$, we can get the Potency. Fiducial limits are calculated according to Finney. Results are shown in Table 7.

\section{Interpreting the results}

The insulin product used was $100 \mathrm{IU} / \mathrm{ml}$ according to the stated potency of the manufacturer but the chemical analysis shows that the results are $97.13 \%, 95.97 \% .93 .61 \%$ and $97.7 \%$ while the biological effect the calculated potency is $91.5,107.7$, 92.9 and $99.7 \mathrm{U} / \mathrm{ml}$. Moreover, all fiducial limits of the biological assay were within the acceptable limits $(80-125 \mathrm{IU} / \mathrm{ml})$ according to British Pharmacopeia 1988.

\section{Conclusion}

Some drugs present chemically in an optimum concentration but when administered to patients it gives undesired results. 
Thus, it is not enough to check the concentration of the active principle of a drug, but the biological activity of this drug in the alive cell also should be checked. Insulin is one of the drugs that can be present chemically but biologically inactive, that is why bioassay should take place. The main purpose of bioassay is comparing one or more drugs with a standardized one. Comparing here is not simple as comparing means in T-test or ANOVA, the latter two methods only show whether there is a significant difference or not. The purpose of comparison when analyzing a drug is to measure its effect as a percentage from the standardized one. To achieve this purpose, a symmetric parallel line completely randomized design is used.

In this study, an estimation of a biological activity of insulin drugs took place by comparing the activity of the insulin in the test preparation by standardized insulin. The potency estimated indirectly by estimating its biological effect that is decreasing the blood glucose level in laboratory mice. The completely randomized design of the parallel linear model took place in this analysis. Using this design was with great benefit in reducing time and effort in analysis. Moreover, RCD is better than using cross-over design as the analysis took place one time on mice, so no data missed. When comparing the results of the biological assay and chemical assay, there was a deviation that is mild in test 3 and 4 , moderate in test 1 , and great deviation in test 2 . However, all the results were within the acceptable limits.

\section{Acknowledgement}

A great thankfulness to all colleagues in Hormone Evaluation Lab at National Organization of Drug Control and Research (NODCAR) for their friendly cooperation, support and unconditional aid. An appreciation is extended to Prof. Wafaa Ahmed Hassan, Hormone Evaluation Lab manager, who offers all facilities for this work, Dr. Marwa Mokhtar Abd Rabo for her generous help in going through pharmacopoeias and finally
Asmaa Said Shahat, Drug analyst, for the technical application of this study.

\section{References}

1. Pharmacopeia US (2017) USP 40 NF 35.

2. Pharmacopoeia B (2017) HM Stationery Office, London, UK.

3. Finney DJ (1952) Statistical method in biological assay. Charles Griffin: London UK.

4. Saha GM (2002) Design and Analysis for Bioassays. In Design Workshop Lecture Notes, ISI, Kolkata, India pp. 61-76.'

5. Hadley ME, Levine JE (2007) Pancreatic hormones and metabolic regulation. Endocrinology. Upper Saddle River, Pearson Prentice Hall Pearson Education Inc 237-263.]

6. Mane K, Chaluvaraju KC, Niranjan MS, Zaranappa TR, Manjuthej TR (2012) Review of insulin and its analogues in diabetes mellitus. Journal of basic and clinical pharmacy 3(2): 283-293.]

7. Pouwer F, Hermanns N (2009) Insulin therapy and quality of life. A review. Diabetes Metab Res Rev 25(S1): S4-S10.

8. Burns C, Morris T, Jones B, Koch W, Borer M, et al. (2010) Proposal to initiate a project to evaluate a candidate International Standard for Human Recombinant Insulin.

9. Lin S, Chien YW (1995) A new bioassay for insulin in conscious rabbits by continuous measurement of glycemic responses. Journal of pharmaceutical sciences 84(6): 742-749.

10. Pharmacopoeia B (1988) HM Stationery Office, London, UK 153.

11. Goyal RK (2008) Principles and Methods of Bioassay'?

12. Bhar L (2016) Efficient block designs for symmetric parallel line assays. Cogent Mathematics 3(1): 1238181.

13. Leonel MDFV, Soares CDV, Siqueira AL (2012) Comparison of pharmacopeial statistical methods applied in microbiological assay for antibiotics potency determination using parallel lines and three-dose level. Brazilian Journal of Pharmaceutical Sciences 48(3): 565-576'

14. Bartlett MS (1937) Properties of sufficiency and statistical tests. Proceedings of the Royal Society of London. Series A, Mathematical and Physical Sciences 160(901): 268-282.

\section{Your next submission with Juniper Publishers}

will reach you the below assets

- Quality Editorial service

- Swift Peer Review

- Reprints availability

- E-prints Service

- Manuscript Podcast for convenient understanding

- Global attainment for your research

- Manuscript accessibility in different formats

( Pdf, E-pub, Full Text, Audio)

- Unceasing customer service

Track the below URL for one-step submission

https://juniperpublishers.com/online-submission.php 